\title{
Reflection
}

\section{The Contribution of Interfaith Dialogue toward a Culture of Peace}

\author{
Jorgen S. Nielsen
}

Dialogue among the adherents of the major world religions has always taken place, especially, but not only, among the Abrahamic faiths: Judaism, Christianity and Islam. Excellent examples of this may be found in the midst of shared histories where we are more often presented with a record of conflicts. The high points must be the enormously rich and creative interactions which took place in medieval Islamic Spain and southern Italy and at various times in places as far apart as Central Asia, Baghdad, Delhi, Cairo and the Ottoman Empire.

As a movement with its institutions and full-time professionals, and networks of activists, interreligious dialogue is primarily a phenomenon of the twentieth century. It is the pressures of this century which have demanded that we mobilize the resources of the great religions for dialogue and peace, purposes which have historically often seemed marginal. In India, the realization that a reasonably unified independence would only be achieved if religions could work together, actually provides a significant impetus towards the cooperation of religious leaders and institutions.

The horrors of Nazi genocide in Europe spurred post-war generations towards a radical review of traditional Christian attitudes towards Judaism. Out of regional tragedies, like the wars in Lebanon and in the former Yugoslavia, have come strengthened efforts across the social spectrum to disarm religious hatreds. The resurgence, in the last couple of decades, of political radicalism motivated by religion and expressed in religious terms,

Jorgen S. Nielsen is a professor of Islamic studies and the director of the Centre for the Study of Islam and Christian-Muslim Relations at the University of Birmingham, UK. This paper was presented at the International Conference on the Dialogue of Civilizations, Institute of Islamic Studies, London, October 27, 2000. 
has spread renewed awareness and experience of destructive interreligious relations among people in all continents.

Above all, the necessity of responding to the processes of globalization and the threats of ecological disaster has brought about a fast-growing realization that religions only have relevance to the extent they can work together for humanity and put aside the contentions of the past. Globalization and migration mean that communities can no longer live in isolation from others; even in countries where there is only one religion, religious pluralism enters via migration, travel, trade, the media, and the Internet.

It is in reaction to such processes that movements for interreligious dialogue have gained growing support. After 1945, Jewish-Christian dialogue found space in a variety of forums, some of which grew into independent agencies and NGOs or were incorporated into existing religious institutions both nationally and internationally. The settlement of Muslim immigrants in Europe led, in some cases, to this being expanded into a JewishChristian-Muslim (JCM) movement with regular programs and events which have now been taking place for several decades. During the 1960s and 70 s the World Council of Churches and the Vatican embarked on major moves towards interreligious dialogue, moves which have made their marks extensively on the whole Christian church and hence, on the societies in which the churches are located.

Virtually every main national and international Muslim organization, as well as many prominent Muslim leaders and scholars, have unequivocally expressed their support for the principle of dialogue and have also actively engaged in moving such dialogue forward. It was noteworthy that virtually every speaker at the 10th annual general Islamic conference, hosted by the Egyptian Ministry of Religious Affairs in July, 1998, spoke of the priority of a dialogue with the Christian West in the coming century. In the World Conference of Religions for Peace (WCRP), all the major world religions were strongly represented, with Buddhists and Hindus playing as active a role as did representatives of the Abrahamic faiths.

But the positive aspect is only part of the picture, and to assume that the way forward is easy would be naive, as it would be to assume that anything like the majority of religious adherents have been convinced. People of religion are readily tempted into presenting religion as offering solutions in spite of all the historical and contemporary evidence that religions are perhaps more often a significant cause of conflict. Or, if they are not the cause, they are easily mobilized into destructive participation when a conflict starts brewing out of social, economic or political causes. Lebanon, 
Yugoslavia, the Caucasus and the Indian subcontinent are immediately obvious recent examples.

The problem arises because adherents of religions, people of faith, are also members of communities with shared material interests and emotional identities which, in some circumstances, can be perceived to be literally matters of life and death, and certainly are often matters which determine comfort and security. Of course, the religious professionals - priests, rabbis, imams, and theologians - are also members of such communities and share these interests and fears. In places where we have recently seen religious conflict, it is, therefore, hardly surprising that religious institutions have sometimes become actively involved on one side or another.

But this also goes some way towards explaining two things about dialogue among the religions. Firstly, one begins to understand why so many might regard it as a threat. People and institutions whose position relies on their recognized right to speak authoritatively in areas of religious teaching and practice, see their positions under challenge, and communities feel inherited certainties are being taken away. But, secondly, this very situation accounts for the sense of urgency being expressed by supporters of religious dialogue. In past centuries, religious exclusiveness caused enough suffering locally, but today clashes between religions have global repercussions.

So how can the task of dialogue make headway, so that religions can become the effective forces for peace which so many of their adherents proclaim them to be? In my view, the task has to be achieved along two parallel interactive tracks with one overriding goal, namely that of taking religion as a cause of conflict out of political and communal relations and reinserting it as a factor for reconciliation and communal development. Both tracks must be pursued simultaneously at all levels, from the street to the palace, so to speak, with universities, religious institutions and the media having particular roles to play along that spectrum.

The first track has to do with the urgency of defusing current and potential community conflicts. Here, a number of different projects take place and can be multiplied and developed. In some countries, local interfaith groups are making a noticeable contribution, while in others, interreligious involvement in development has shown the potential for success. For example, political action against discrimination in employment, or access to health, education, and social welfare, etc., represent different ways by which people of different religious commitments have come together around a shared sense of justice. 
But the urgency also requires that the media - print and electronic - be persuaded to look beyond the immediately sensational. We have spent decades both condemning the media for their sensationalism, lack of responsibility and dependence on one or another center of power, and making recommendations for the improvement of their behavior. This is easy, precisely because the media so often are guilty as charged. However, we seem to have achieved virtually nothing by condemnation and recommendation. Some of us have sought instead to recognize and cooperate: recognize those newspapers, journalists or program makers who actually want to act with a degree of responsibility and impartiality, and cooperate with them by involving them in our work, engaging them in conversation, helping them to understand what they are trying to write about. I have seen it work successfully more than once, but it requires patience: results are not achieved overnight.

In the universities there are tasks especially for social and political scientists, and probably psychologists: although psychology is an explosively sensitive area. In Europe and North America, in particular, the social and political sciences have until recently tended to ignore religion as a dying ember of the past: these were the secular sciences par excellence. As a result they have often been taken completely by surprise when religion suddenly returns to the forefront of some political event. They have thus had great difficulty in coming to terms with, for example, the political resurgence of Islam. But the situation is changing - this conference is just one evidence of that - and increasingly scholars in these disciplines are beginning to take the religious factor seriously. I am sure that the academic network on religion and society that UNESCO is encouraging (with which my university is looking forward to working), will make a significant contribution to this change.

The second track is a long-term vision. Among the Abrahamic faiths, as also, for example, between Hinduism, Sikhism, and Islam, we have accumulated centuries of baggage out of which we tend to remember the bad times and use them as ammunition against each other in subsequent conflicts. In good times this negative baggage is stored away, but it does not take much to recall it, so that a battle in 1389 in the Balkans becomes again a live landmine in modern Yugoslavia, or one in Ireland in 1689 becomes the central symbol of conflicting communal identities three centuries later. I am sure we can all identify similar past events which refuse to remain safely in the history books. The long-term project must be to change that baggage. We cannot discard it, but since the human need for a sense of 
identity rooted in shared symbols and experiences needs baggage, we can make conscious efforts to change it, or rather its meanings, just as they have been changed in the past.

Here we are talking, in the first instance, of an academic activity involving first and foremost the historians and theologians. The historians have to rediscover and reinterpret our various histories and the histories of their interaction. Very few historians would make von Ranke's claim that it is possible to rediscover the past as it really was, and most would admit that they cannot isolate themselves from their own historic time and its perspectives, assumptions and preoccupations. Through their emphasis on real and imagined differences among different entities in Europe, historians were major contributors to the growth of nations and nationalism, and the requirements of the nation in turn set the research agendas of the historians. The twentieth-century interest in the Crusades in the Middle East can be directly attributed to twentieth-century preoccupations, which have influenced both the choice of research subjects and their interpretation. In contrast, I would claim that there is a shared history across the Mediterranean which is much stronger than the separate ones to which we have become accustomed. Furthermore, as a historian myself, I see nothing wrong in encouraging research in that shared history for reasons of presentday needs, so long as one does not surrender critical norms for the sake of partiality.

Similar comments can be made about theologians and religious thinkers. One can look at the tenets and foundational texts of most religions and discover aspects which have been subjected to highly developed scholarship over generations, while others have hardly moved beyond the original bare statements of belief, injunction or advice. The topics which have been elaborated, and the ways in which they have been elaborated, can usually be shown to have been chosen in response to particular needs of the religious community at a particular time. And so other aspects, other dimensions, have, in a sense, lain dormant, held in reserve until such time as they might be needed.

At this point we need also to recruit the educationists into the project. It is they, their teaching, especially in the primary and early secondary schools, and their textbooks, which have in the past handed down ideas set in one generation to the next generation. They must now be persuaded and trained to pass on interpretations and approaches which are more appropriate for the twenty-first century. This is a particular problem in terms of politics, logistics and resources. We know how long it takes for the results of 
academic research, especially in the arts and humanities, to filter across into the school curriculum, the training of teachers, and the production of teaching resources. Where politicians may find it safe to leave academics to get on with their work, it is much less safe to let their ideas take over among the teaching profession: this would give us direct access to the future majority of the population and often upset the parents in the process. And if the state determines that a new approach to a subject is required, it takes an enormous amount of investment and time before the change has been reasonably and successfully achieved. In Britain it took two decades of teacher training and curriculum development before a multifaith religious education curriculum eventually became accepted as the norm.

Here one might also draw special attention to the impact of the training of the religious professionals, priests, imams, religious teachers etc., a particularly sensitive field because few states relish the risk involved in trying to interfere on this point. Clearly this is an arena where patient persuasion and dialogue is required, and where an overlap between universities and the religious training conducted in seminaries creates a direct link which can have more chance of success.

On both of these tracks - the short-term and the long-term - the dialogue is the end; but it is also the means. All such projects have to be shared between people from the faiths concerned. This is obviously the case in the practical, academic and educational projects indicated. But I would argue that it must extend also to the theological task by which scholars and thinkers from various religions work together, not only on their mutual views, but also on involving the outsider in their own internal theological rethinking. Only by thus internalizing the other, can a religion become a full, permanent, and complete actor in a culture for peace. 